\title{
Leading-edge Receptivity to a Vortical Freestream Disturbance: A
}

\section{Numerical Analysis}

Thomas A. Buter

Helen L. Reed

Arizona State University

Tempe, $\mathrm{Az}$

N92-14971

\section{ABSTRACT}

The receptivity to freestream vorticity of the boundary layer over a flat plate with an elliptic leading edge is investigated numerically. The flow is simulated by solving the incompressible Navier-Stokes system in general curvilinear coordinates with the vorticity and stream function as dependent variables. A finitedifference scheme which is second-order accurate in both space and time is used. As a first step, the steady basic-state solution is computed. Then a small amplitude vortical disturbance is introduced at the upstream boundary and the governing equations are solved timeaccurately to evaluate the spatial and temporal growth of the perturbations leading to instability waves (Tollmien-Schlichting waves) inside the boundary layer. Preliminary results for a symmetric, 2-D disturbance reveal the presence of TS waves aft of the flatplate/ellipse juncture for an aspect ratio 6 leading edge subject to a nondimensional forcing frequency of 230 .

\section{Nomenclature}

U freestream velocity

L half-thickness of the plate

$v \quad$ kinematic viscosity

Re Reynolds number, UL/v

$\omega \quad$ frequency of oscillations

$\mathrm{F}$ dimensionless frequency parameter,

$$
\omega v / \mathrm{U}^{2} \times 10^{6}
$$

AR aspect ratio of the semi-ellipse

TS Tollmien-Schlichting

This work is supported by the Air Force Office of Scientific Research and NASA Langley Research Center. 


$\begin{array}{ll}\text { FS } & \text { freestream } \\ X, Y & \begin{array}{l}\text { dimensionless Cartesian coordinates parallel and normal to } \\ \text { the plate, respectively }\end{array} \\ V & \text { perturbation velocity vector } \\ u^{\prime} & \text { streamwise perturbation velocity } \\ v^{\prime} & \text { normal perturbation velocity } \\ w^{\prime} & \text { perturbation vorticity } \\ A & \text { disturbance amplitude coefficient } \\ \eta & \text { distance along far-field boundary line } \\ \eta_{0} & \text { specified mid-point of disturbance } \\ \sigma & \text { application line } \\ & \text { stretching parameter }\end{array}$

\section{Introduction}

Boundary-layer stability and transition remains one of the major unsolved research areas in fluid mechanics at the time of this publication. It is of considerable importance with regard to a myriad of technological applications. Linear stability theory has been applied extensively in the design of laminar flow control (LFC) systems to delay or even eliminate boundary-layer transition. LFC can provide major increases in the performance of both acrodynamic and hydrodynamic systems (Bushnell and Malik, 1985). Transition modeling, which encompasses the accurate prediction of the location of transition and the mechanisms which induce it, is crucial to flow systems which have both laminar and turbulent regions. In a lowdisturbance environment, transition in boundary-layer flows is usually initiated by the unbounded growth or instability of small disturbances in the boundary layer. Boundary-layer stability theory describes the development of these self-excited or free oscillations in the laminar boundary layer. However, these free or self-excited oscillations are usually initiated by some externally forced disturbances such as freestream turbulence or sound.

Receptivity, the process by and through which these externalforced disturbances enter the boundary layer and lead to unstable waves, thus plays an important role in stability and transition studies. Much of what is understood regarding the nature of boundary-layer receptivity stems from the high-Reynolds-number asymptotic analysis conducted first by Goldstein and colleagues $(1983,1985,1989)$ and extended by Kerschen and colleagues $(1988,1990,1991)$. They and their colleagues have identified that the conversion of the typically longwavelength freestream disturbances to TS instability waves occurs in regions of the boundary layer where there exist rapid local variations of geometry and/or local flowfield in the streamwise direction. Much 
of their work has concentrated on the effect of acoustic disturbances in the leading-edge region and regions with short-scale variations in surface geometry. Kerschen(1991) has presented results of such an analysis for the case of a convected gust. Their analysis has been used to aid in the interpretation of experimental results obtained, in general, on flat-plate models having elliptic leading edges. Nishioka and Morkovin(1986) present a detailed review of some receptivity experiments. Recent work by Kendall(1991) in which he studies the receptivity problem for the case of freestream turbulence(FST) and ongoing work by Parekh et al(1991) also concentrate on similar geometries of varying aspect ratio. Kendall has seen evidence of a TS structure but experimentalists have, in general, found it difficult to isolate a TS component in their measured signal. Much of the difficulty may stem from the complex nature of the background flow found in even the most sophisticated wind tunnels and therefore in quantifying the true disturbance environment (Saric,1990).

With the advent of powerful supercomputers and numerical algorithms, the numerical solution of the full unsteady Navier-Stokes equations is fast becoming an integral tool for the study of the receptivity phenomena. One advantage of this technique is that one has complete control of the disturbance environment and is therefore able to isolate particular kinds of disturbances and study their individual effects(Lin,1989). There have been several successful numerical works in receptivity to local disturbances, e.g. Fasel et al(1987).

In the case of freestream disturbances, Kachanov et al.(1978) solved the incompressible flow over an infinitely thin, semi-infinite flat plate, using a finite-difference method to solve the Navier-Stokes equations linearized for small disturbances. A von-Karman vortex street with its core far from the boundary layer and transverse acoustic waves across the leading edge were considered. Murdock (1980) solved the full Navier-Stokes equations in parabolic coordinates for flow over an infinitely thin flat plate, using a spectral finite-difference method and in a 1981 paper presented results for the flow over parabolic bodies (with favorable pressure gradient) Gatski and Grosch(1987) solved the full incompressible Navier-Stokes equations using finite differences, for flow over an infinitely thin, semi-infinite flat plate. Plane longitudinal sound waves were considered, however no clear conclusions as to the development of the TS wave were presented. Lin (1989) numerically simulated the receptivity of the flow over a semi-infinite flat plate with an elliptic leading edge to a plane acoustic disturbance for a series of leading edge aspect ratios. His results indicated a development of TS waves in the boundary layer, with amplitudes which decreased with increasing aspect ratio. Lin et al. (1991) also investigated the role of the discontinuity in curvature present at the 
ellipse flat-plate juncture and found that for a smoothed juncturecurvature, the amplitude of the TS waves was roughly halved.

To our knowledge, unsteady flow over a flat plate including the leading-edge curvature has not been solved numerically for the case of freestream vorticity. This leading-edge curvature region, with inherent pressure gradients and large tangential velocity component, has been shown by $\operatorname{Lin}(1989,1991)$ to play a vital role in receptivity to freestream disturbances. In this work, an attempt is made to numerically simulate the receptivity of a two-dimensional boundary layer to freestream vorticity and a brief description of the approach taken is presented in the next section.

\section{Numerical Formulation}

The present work is an attempt to investigate the initial stage, receptivity, of the transition process on a semi-infinite flat plate for an incompressible flow, by direct numerical solution of the governing Navier-Stokes equations, here cast with vorticity and stream function as dependent variables. Following the work of Lin(1989), a C-type orthogonal grid is generated around the elliptic leading edge and flat plate(Figure1). This mesh is structured in such a way as to allow the introduction of a small, localized vortical disturbance at the far-field boundary near the basic-state stagnation line(Figures $2 a \& b$ ), yet maintain sufficient resolution of the flat-plate and juncture regions where the development of the instability waves is expected. As the surface curvature is changing rapidly (and is in fact discontinuous at the juncture) the mesh is particularly fine in this region. A hyperbolictangent stretching function is used to insure that no fewer than 12 points in the streamwise direction lie within the expected TS wavelength all along the flat plate. The equations and boundary conditions are written in general curvilinear coordinates and discretized in space and time, using second order finite differences. The Modified Strongly Implicit Procedure (MSIP) of Schneider and Zedan(1981) is used and is found to be robust and stable for reasonably small time steps.

Initially, the basic-state flow is calculated presuming the following flow conditions: the flow is steady, incompressible with a uniform freestream. The basic-state boundary conditions are as follows: the no-slip and no-penetration conditions are applied at the wall, a symmetric boundary condition along what amounts to the basic-state stagnation line (a zero incidence case is considered) is employed, and inviscid velocities are specified at the far-field boundaries. At the downstream boundary, a homogeneous second-derivative boundary condition following Fasel(1976) is used. 
The basic-state, upon application of the afore-mentioned boundary conditions, is solved using a transient approach and spatially varying time steps. Once a basic-state solution is obtained, a smallamplitude ( $u^{\prime} \max / U=4 \times 10^{-3}$ ), periodic, localized disturbance is applied as an unsteady boundary condition at the far-field boundary. The resulting unsteady flow and the temporal and spatial development of the perturbations are determined by solving the governing equations subject to this modified boundary condition time accurately. Current results are presented in the following section.

\section{Results and Discussion}

The steady-state solution is obtained for an aspect-ratio( $A R)=6$ semi-ellipse. The Reynolds number(Re), based upon the half-thickness of the leading edge and the freestream velocity $U$ is 2400 . The downstream boundary of the computational domain is chosen such that the branch I of the neutral stability curve (according to linear parallel theory) lies well within the computational domain. The farfield computational boundary is placed such that it is 20 boundary-layer thicknesses from the plate in the downstream region. The mesh size used in the present analysis is 260 points in the tangential direction and 100 points in the normal direction, although a calculation for a mesh of $360 \times 100$ yielded an identical result for the basic-state calculation. Wall vorticity is presented in Figure 3 . Nearly Blasius flow is recovered in the flat-plate region as evidenced by the streamwise velocity profiles depicted in Figure 4.

The unsteady calculation was carried out for a dimensionless frequency parameter $F=230$. The forcing amplitude applied has a maximum streamwise velocity perturbation of $\left(u_{\max }^{\prime} / U\right)=4 \times 10^{-3}$. The disturbance was introduced over a small region just above the stagnation line along the farfield boundary in the form of a periodic boundary condition cast in the following form:

$$
w^{\prime}=-A\left[\left(\frac{4\left(\eta-\eta_{O}\right)-2}{\sigma}\right) e^{-\left(\eta-\eta_{o}\right)^{2} / \sigma}\right] \sin (\omega t)
$$

Note that this represents the vorticity associated with the introduction of a perturbation of velocity normal to the farfield boundary. The velocity perturbation is specified such that it is symmetrical about a specified location along the farfield boundary, $\eta_{0}$, so that no net mass is introduced into the domain. The disturbance was found to propagate downstream, as expected, at the convective 
speed and as such the wavefront of the disturbance reached the downstream boundary during the 6 th cycle of forcing. Figure 5 is a presentation of instantaneous disturbance streamlines observed at the end of a series of cycles of forcing which reveal the quasi-steady structure of the solution over much of the plate following 6 cycles. A temporal Fast Fourier Transform (FFT) analysis conducted over several cycles also confirmed the quasi-steady nature of the flow after 6 cycles. In figure 6 typical $u$ '-velocity profiles are displayed and in figure 7 the change of $u^{\prime}$ with $X$ is presented. From these figures it is evident that the signal is a complex combination of more than one wave. In an attempt to extract some information regarding the specific components of this signal, some educated assumptions were applied. Kerschen points out that the freestream vorticity will decay exponentially as one approaches the wall. This is evident in the streamwise $u^{\prime}$ plots(figure 7). Note the change in signal wavelength with distance from the wall. Near the wall, the signal wavelength is less than half of that found in the freestream and, qualitatively, the wavelength of the signal appears to approach that of the TS wave. Thus, to better assess the nature of the disturbance, spatial correlations with signals of freestream and predicted TS wavelength were conducted. In figure $8, a$ series of correlations between the total signal and a signal with a wavelength based on forcing frequency and freestream velocity at different $Y$-locations is presented. Clearly, this correlation supports our supposition that the direct contribution of the freestream perturbation to the total signal near the wall is minimal. If one then, as a first guess, presumes the signal wavelength one point from the wall to be that of the TS wave(a length as it turns out very close to that which is predicted by linear theory), then one can use the correlation with this wavelength to determine the phase of this portion of the signal. Phase information for this portion, hereafter referred to as the TS portion of the total signal, is presented in figure 9 for a representative $X$-location aft of the juncture Note the $180^{\circ}$ phase shift which is associated with the TS wave. A comparison with the total signal phase(obtained from a temporal FFT over one cycle of forcing) with that obtained for the freestream and TS components is displayed in figure 10. Note that the total signal and the 'TS' are in-phase near the wall, as expected, but as one moves away from the wall, the freestream portion of the signal begins to dominate. The correlation can also give a rough estimate of the signal amplitude, which again displays the characteristic TS mode shape (Figure 11). If one uses the phase information obtained from the spatial correlations in concert with the temporal FFT of the total signal, an estimate of the respective component amplitudes which accounts for signal modulation with $\mathrm{X}$ may be obtained. Amplitude plots are presented in Figure 12 for 
a series of X-stations using this technique. As a measure of the receptivity of the disturbance, one may compare the ratio of the maximum TS amplitude to that of the disturbance in the freestream. From this analysis we find that for an $A R=6$ leading edge at a forcing frequency $F=230$, the receptivity is of order $10^{-1}$.

\section{Conclusions}

Preliminary results from a numerical simulation of the receptivity of a two-dimensional laminar boundary layer to a symmetric vorticity wave in the freestream suggest the presence of TS waves aft of the ellipse-flat-plate juncture. While the signal decomposition technique is imprecise, the receptivity, based on maximum TS amplitude to freestream amplitude, is estimated to be of order $10^{-1}$. In addition to a more detailed analysis of the current result to include a comprehensive grid study and an analysis of the leading edge flowfield, studies of the effect of disturbance position, amplitude, frequency, leading-edge aspect ratio, and the effect of juncture curvature are planned. Similar cases will be investigated for the particularly interesting case of an asymmetric disturbance. Also in progress is a repeat of this case on a computational domain which extends past branch II.

\section{Acknowledgements}

The first author would like to thank Mr. Ray-Sing Lin and Mr. Nay Lin for countless stimulating discussions and for their many helpful comments regarding a number of key technical points found in this article. The authors would also like to thank Professor William S. Saric for many helpful ideas and suggestions.

\section{References}

Bushnell, D.M. and Malik, M.R. 1985 "Application of stability theory to laminar flow control-progress and requirements", In Proc. Symp. on the Stability of Time Dependent and Spatially Varying Flows (ed. D.L. Dwoyer \& M. Y. Hussaini), pp. 1-17.

Fasel, H. F. 1976 "Investigation of the stability of boundary layer by a finite difference model of the Navier-Stokes equations", J. Fluid Mech. 78, 355-383. 
Fasel, H. F., Rist, U. and Konzelmann, U. 1987 "Numerical investigation of the three-dimensional developments in boundary layer transition", AIAA paper 87-1203.

Gatski, T. B. and Grosch, C. E. 1987 "Numerical experiments in boundary-layer receptivity", Proc. Symp. on the Stability of Time Dependent and Spatially Varying Flows, Springer-Verlag, 82-96.

Goldstein, M. E. 1983 "The evolution of Tollmien-Schlichting waves near a leading edge", J. Fluid Mech. 127, 59-81.

Goldstein, M. E. 1985 "Scattering of acoustic waves into TollmienSchlichting waves by small streamwise variations in surface geometry", J. Fluid Mech. 154, 509-530.

Goldstein, M. E. and Hultgren, L. S. 1989 "Boundary-layer receptivity to long-wave freestream disturbances", Ann. Rev. Fluid Mech. 21, 137-166.

Heinrich, R. A. E., Choudhari, M. and Kerschen, E. J. 1988 "A comparison of boundary layer receptivity mechanisms", AIAA paper 88-3758.

Kachanov, Yu. S., Kozlov, V. V. and Levchenko, V. Ya. 1978 "Occurrence of Tollmien-Schlichting waves in the boundary layer under the effect of external perturbations", Izv. Akad. Nauk. SSSR. Mech. Zhid. i Gaza, 5, 85-94 (in Russian). (Transl. 1979, Fluid Dyn. 13, 704-711).

Kendall, J. M. 1991 "Studies on laminar boundary-layer receptivity to freestream turbulence near a leading edge", FED-Vol. 114, Boundary Layer Stability and Transition to Turbulence, ASME.

Kerschen, E. J. 1991 "Linear and non-linear receptivity to vortical freestream disturbances", FED-Vol. 114, Boundary Layer Stability and Transition to Turbulence, ASME.

Kerschen, E. J. and Heinrich, R. A. 1990 "Boundary layer receptivity theory", Appl. Mech. Rev. vol. 43, no. 5. part 2, S152-157.

Lin, N. 1989 "Receptivity of the boundary layer on a semi-infinite flat plate with an elliptic leading edge", M. S. Thesis, Arizona State University. 
Lin, N., Reed, H. L., and Saric, W. S., 1991 "Leading-edge Receptivity: Navier-Stokes computations", Boundary Layer Transition \& Control Conference, Peterhouse College, Cambridge, United Kingdom.

Murdock, J. W. 1980 "The generation of Tollmien-Schlichting wave by a sound wave", Proc. R. Soc. London. A 372, 517-534.

Murdock, J. W. 1981 "Tollmien-Schlichting waves generated by unsteady flow over parabolic cylinders", AIAA paper 81-0199.

Nishioka, M. and Morkovin, M. V. 1986 "Boundary-layer receptivity to unsteady pressure gradients: Experiments and overview", J. Fluid Mech. 171, 219-261.

Parekh, D. E., Pulvin, P., Wlezien, R. W. 1991 "Boundary Layer Receptivity to convected gusts and sound", FED-Vol. 114, Boundary Layer Stability and Transition to Turbulence, ASME.

Saric, W. S. 1990 "Low-speed experiments: requirements for stability measurements", Instability and Transition, Vol. I., SpringerVerlag, pp162-174.

Schneider, G.E. and Zedan, M. 1981 "A modified strongly implicit procedure for the numerical solution of field problems", Numerical Heat Transfer, 4, 1-19. 


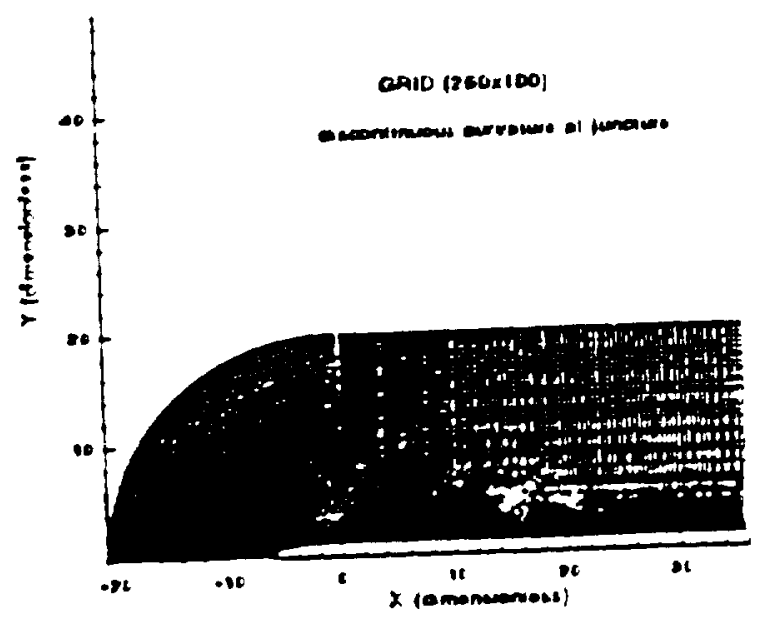

Figure 1. C-EFid used in computations.

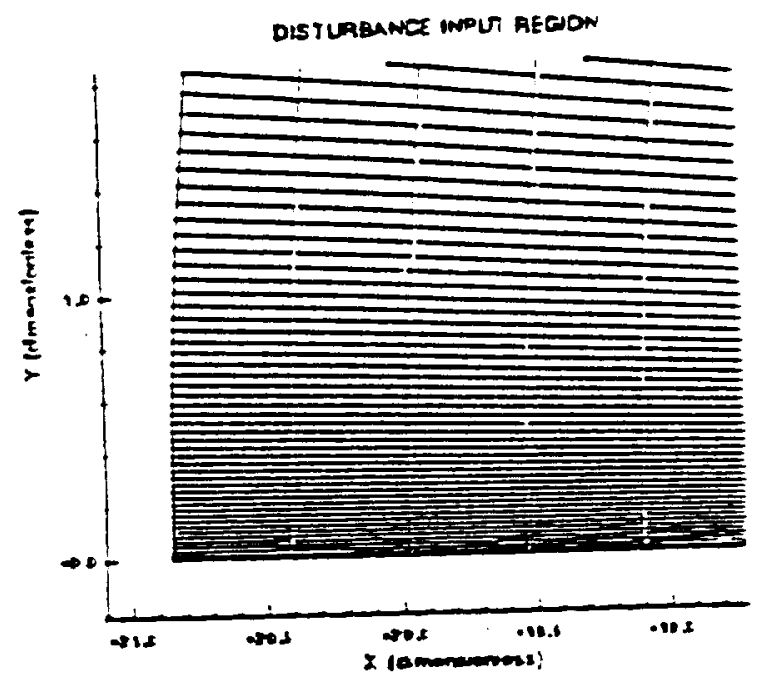

Figure 2r. Bion-ug of cisturbance inpu: region. 


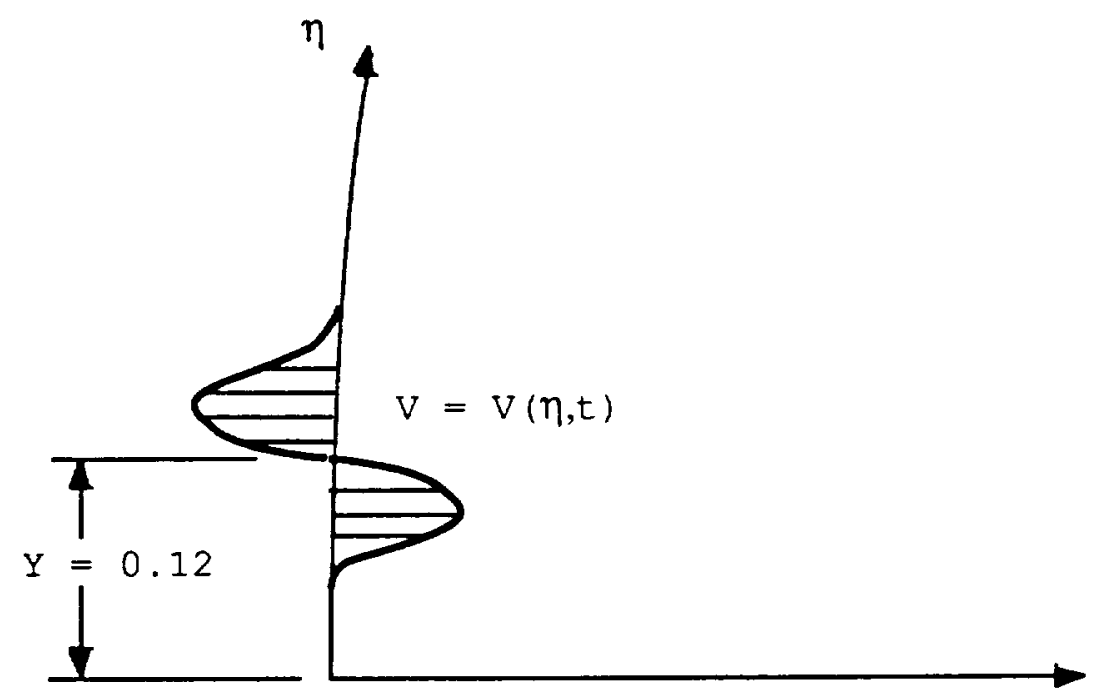

Figure $2 b$. Schematic of disturbance velocity profile at input location. ( $V$ has both $a u^{\prime}$ and $v^{\prime}$ component).

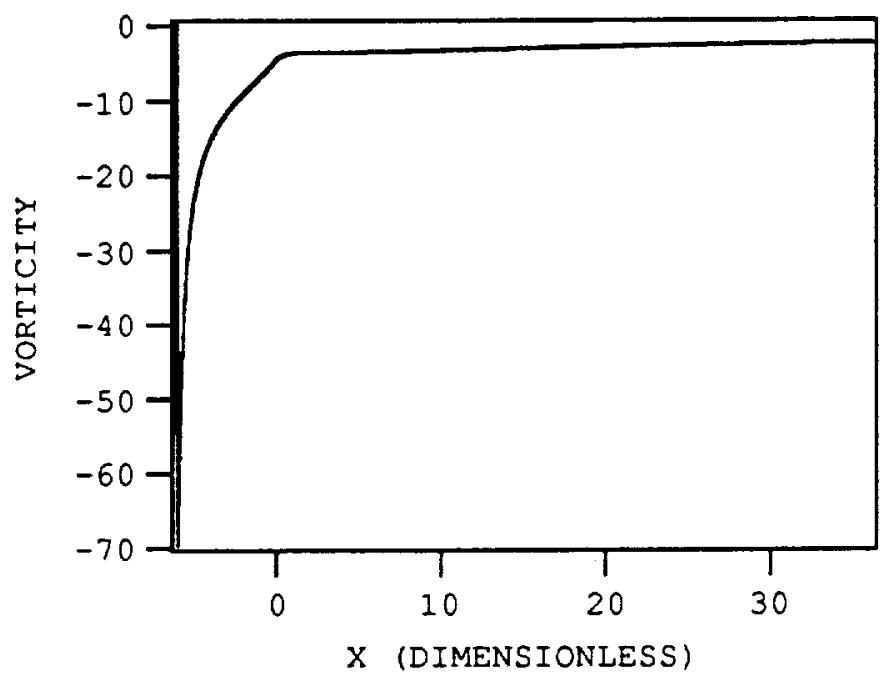

Figure 3. Basic state wall vorticity. 

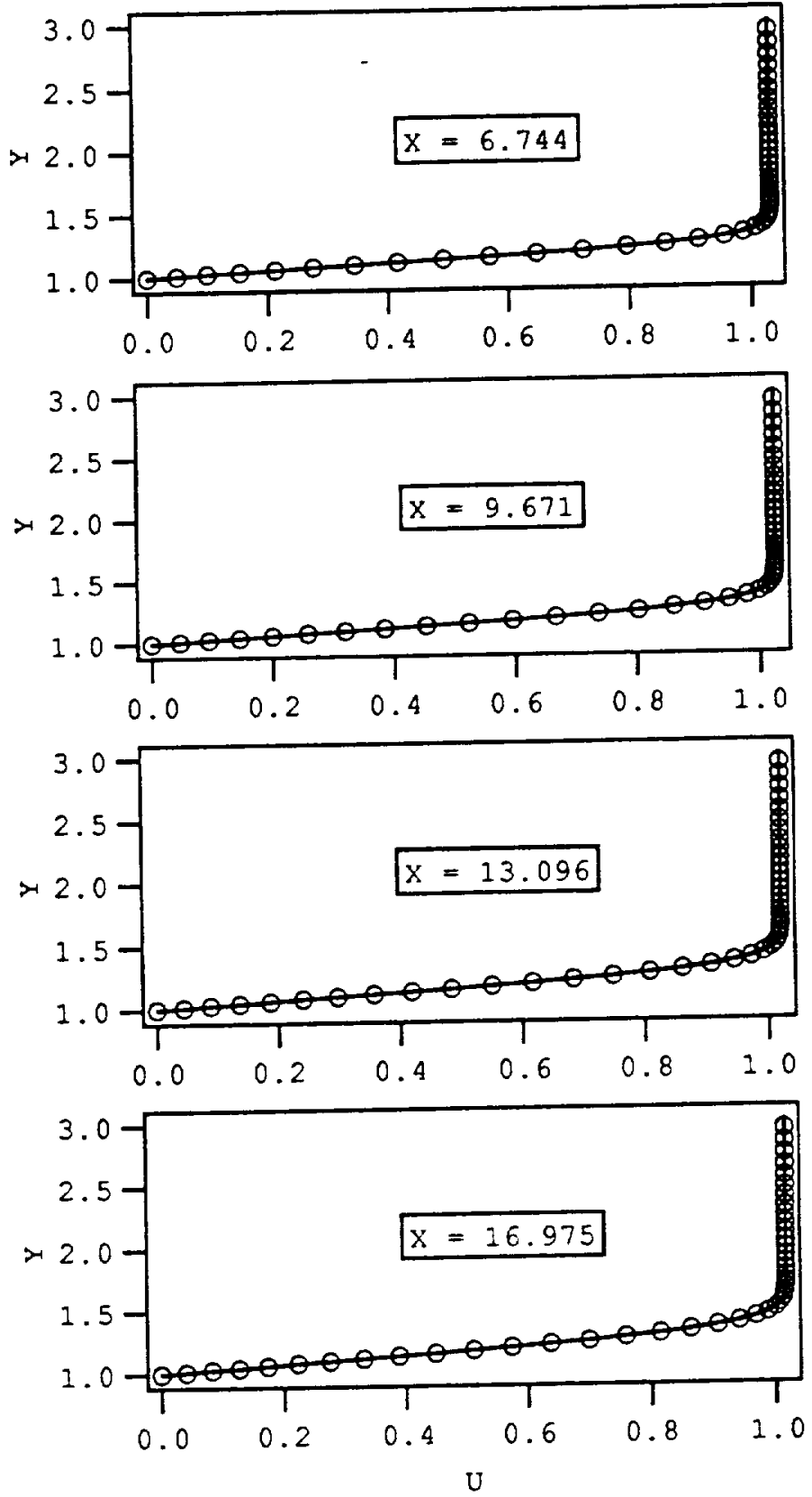

Figure 4. Streamwise basic-state velocity profiles.

The body surface is located at $Y=1$. 

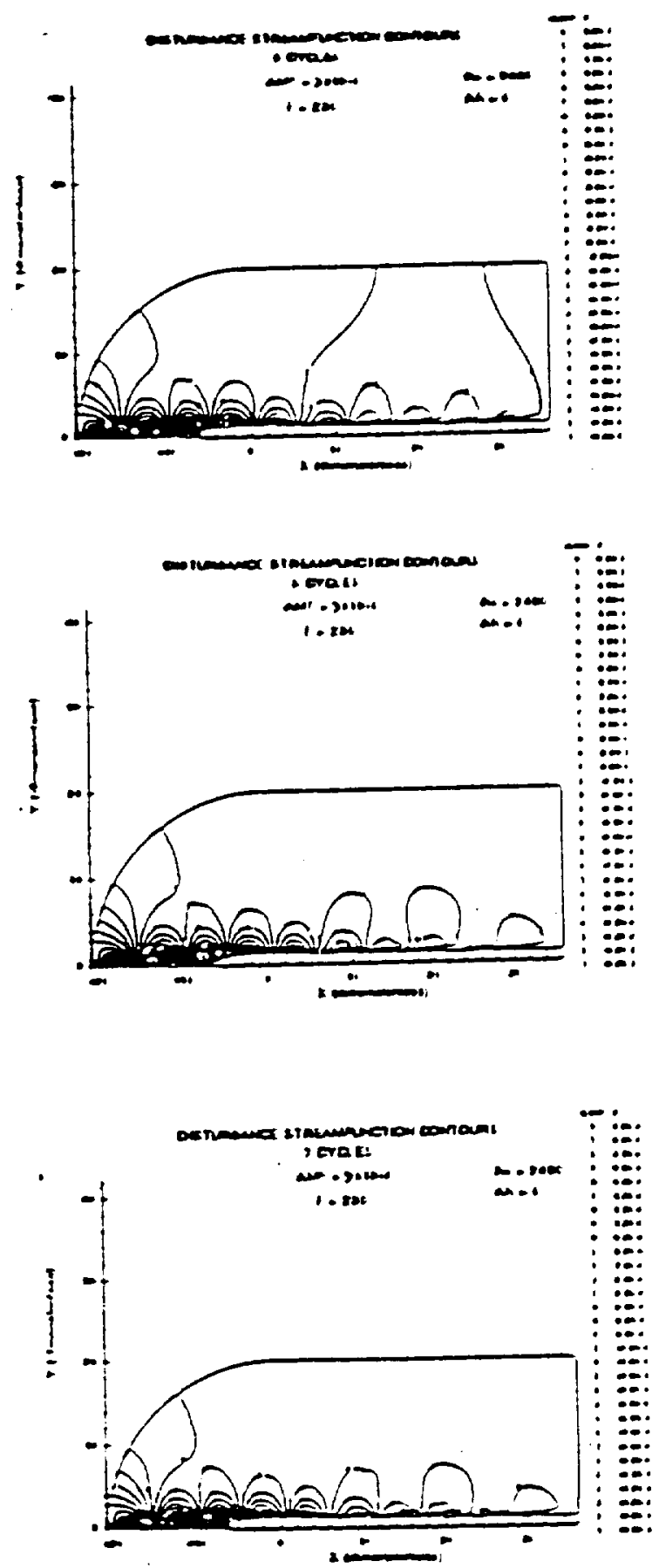

Figure 5. Disiurbance Sireanfunciton contours Efie: 5 it., 6it end ith cycles of forcing. 

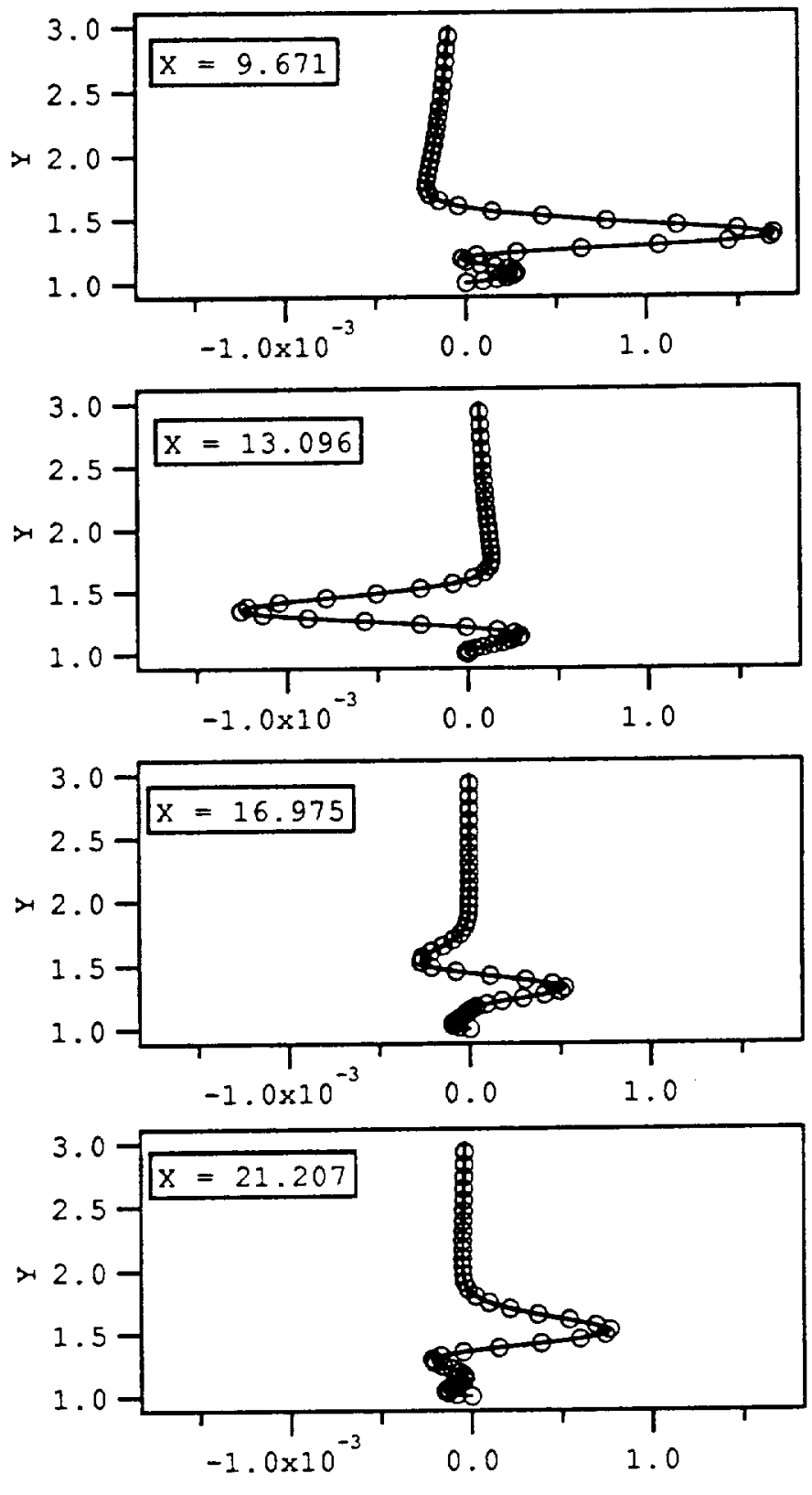

Figure 6. Streamwise-perturbation velocity profiles after 9 cycles of forcing. 

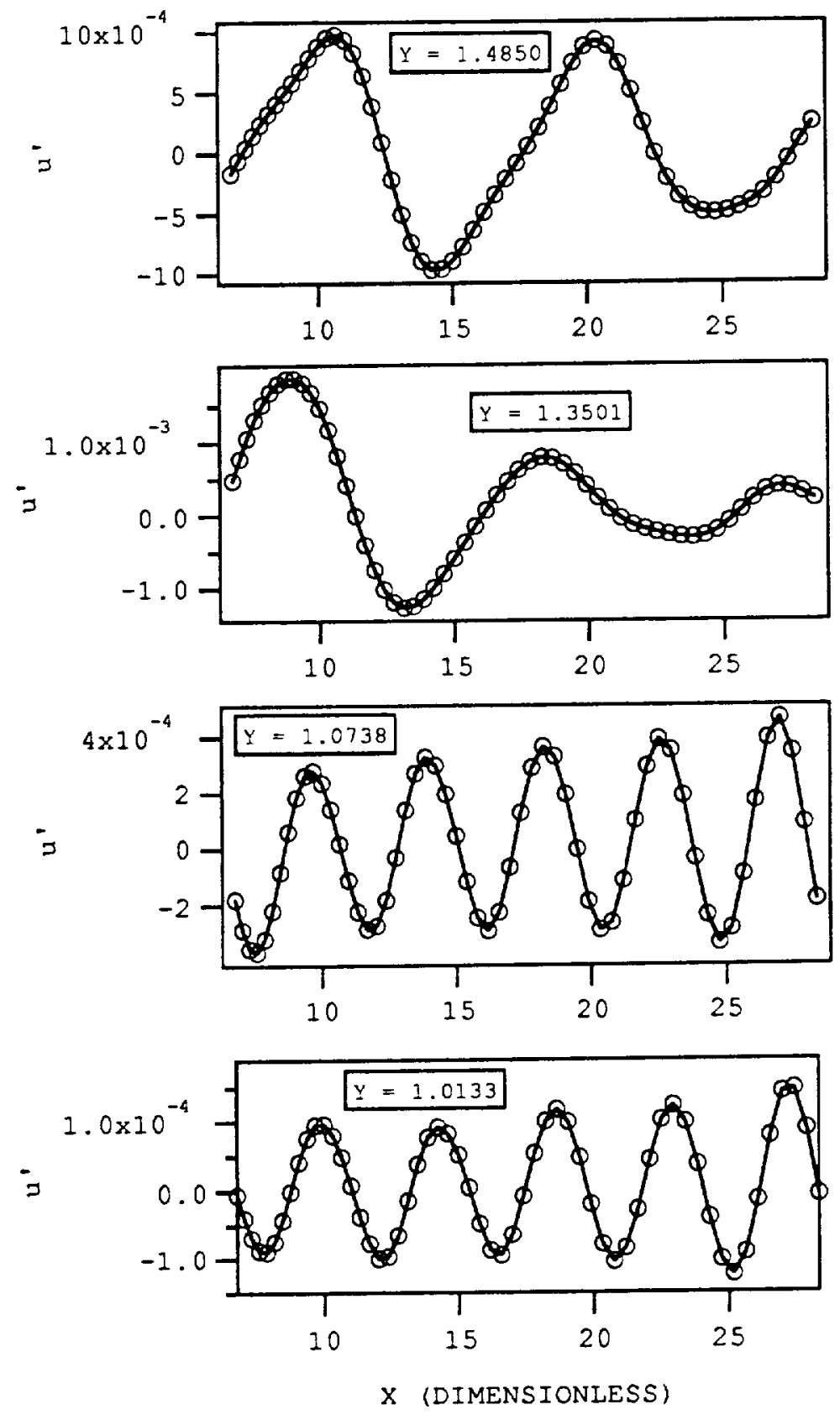

Figure 7. Streamwise-perturbation velocity profiles after 9 cycles of forcing. 

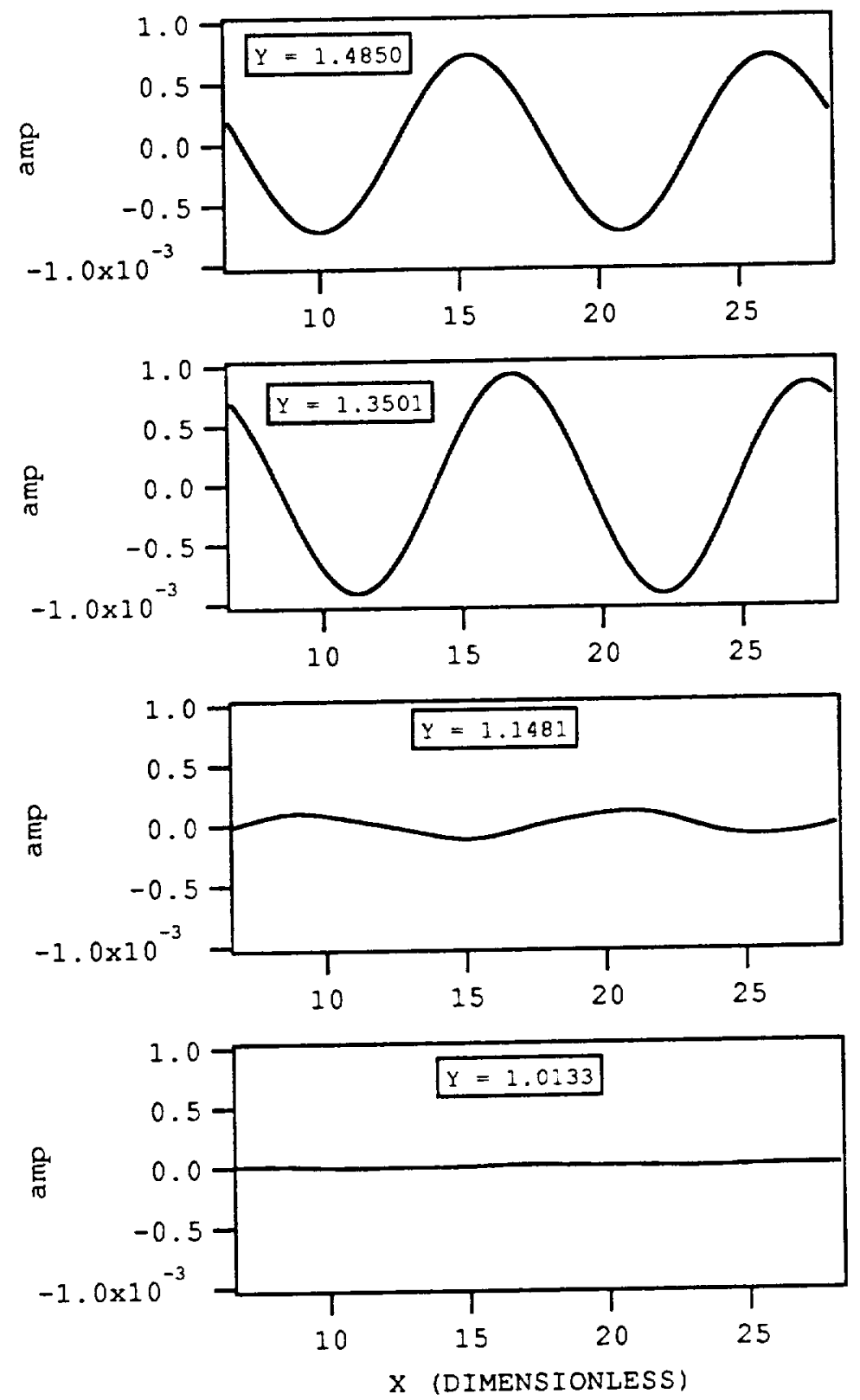

Figure 8. Spatial correlation of the total signal with a signal of freestream wavelength. 


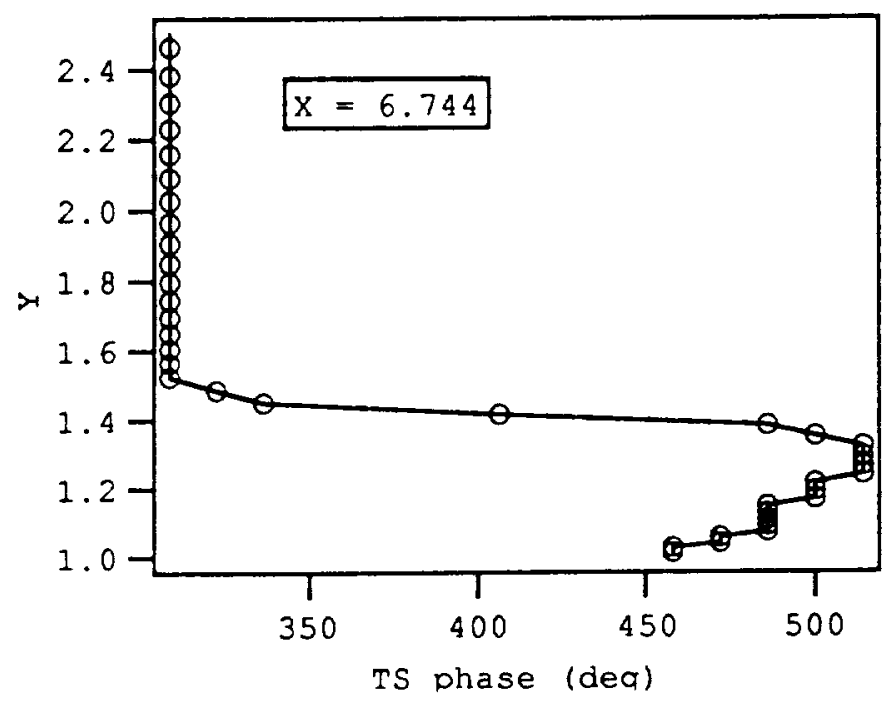

Figure 9. Phase of TS component of signal based on correlation of total signal with a signal of TS wavelength.

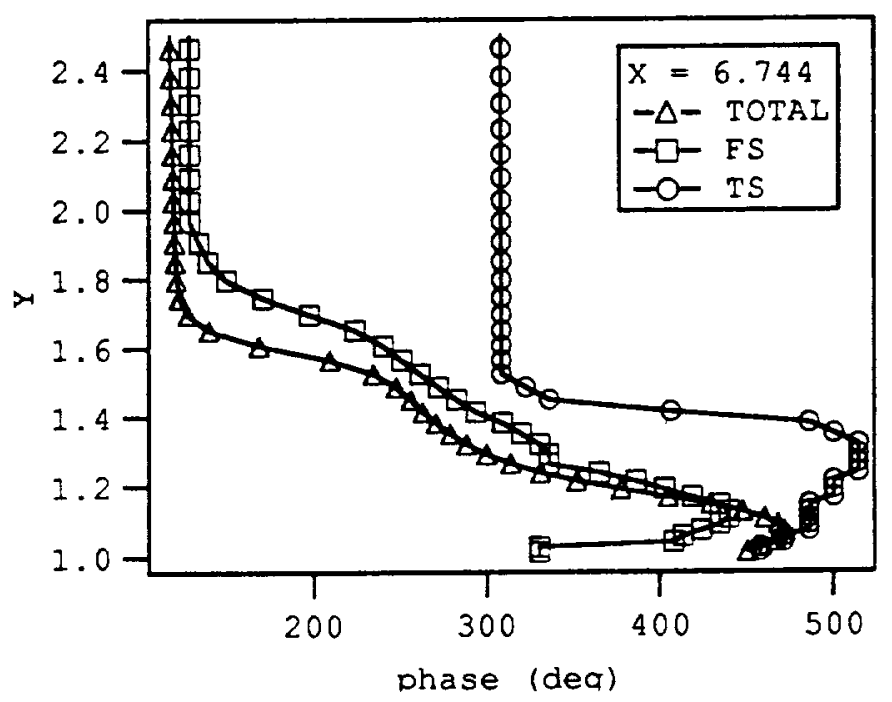

Figure 10. Comparison of component phases to total signal phase. 


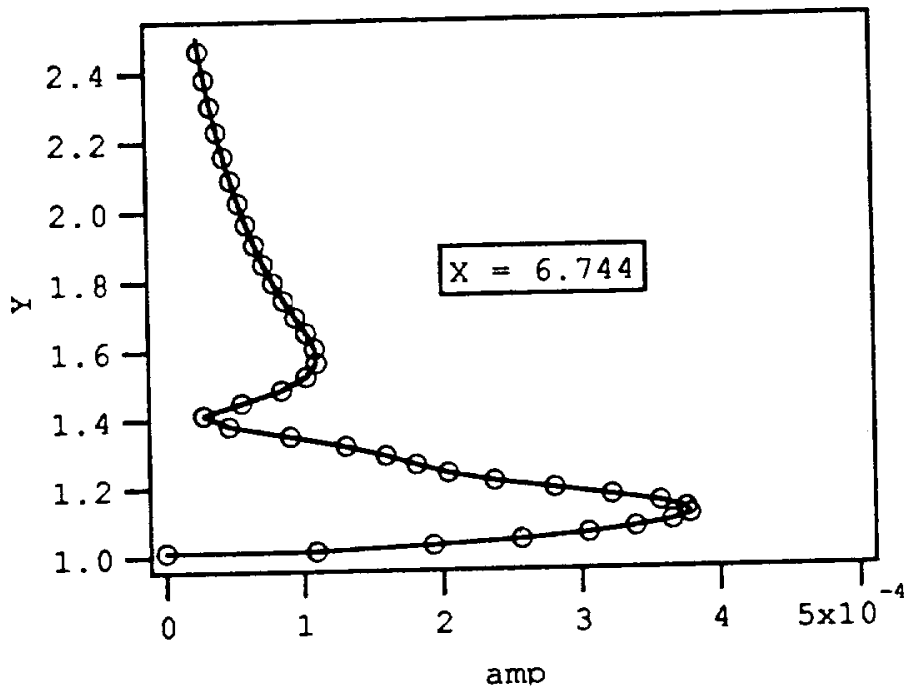

Figure 11. Estimate of TS amplitude based on spatial correlation with signal of TS wavelength. 

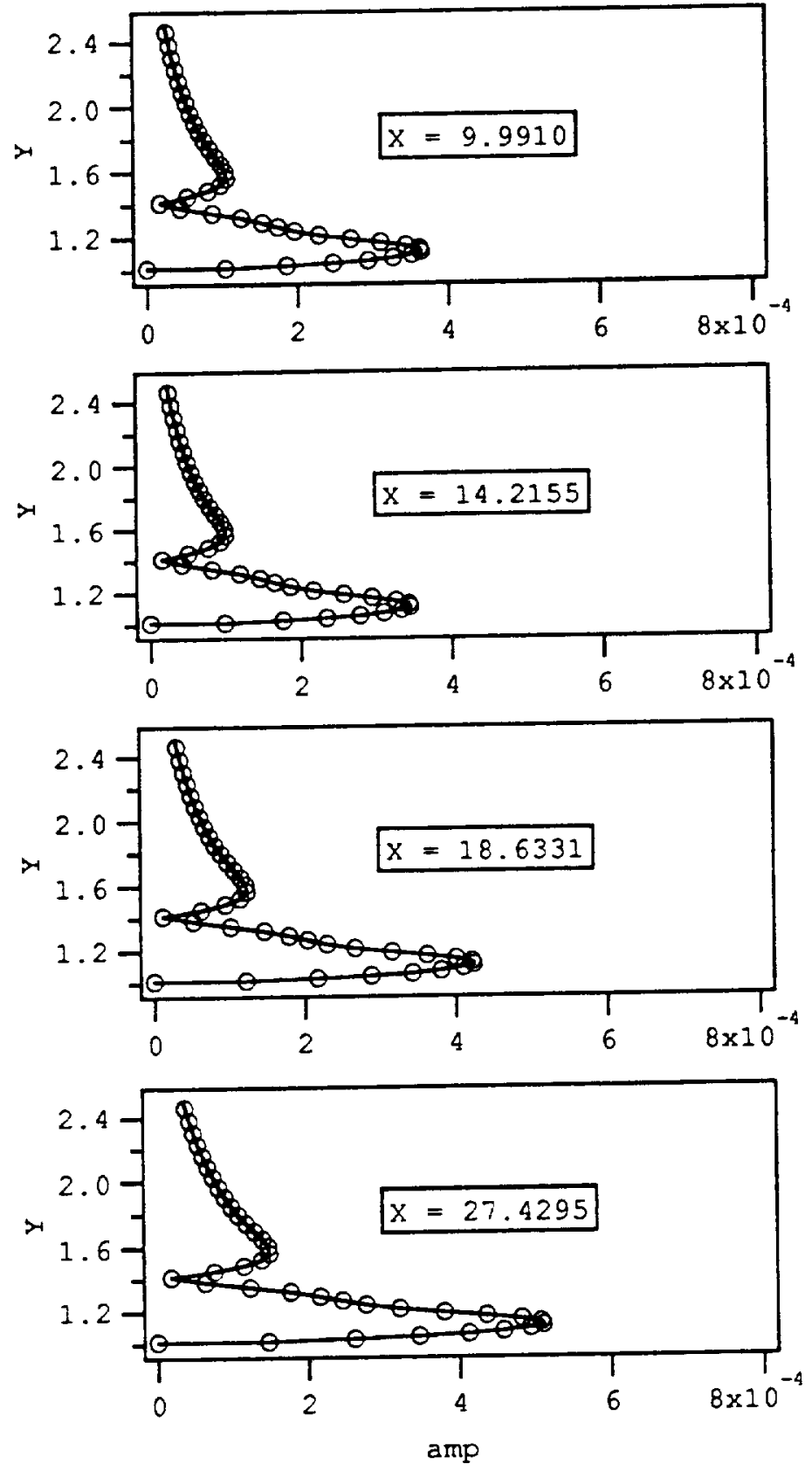

Figure 12. Estimate of TS amplitude profiles using temporal FFT signal and correlation phase angles. 


\section{RESOURCES AND PERSONNEL}

One of the principal strengths of our team at Arizona State University is its broad skills in analysis, computations, and experiments. We facilitate day-to-day communication between the computational work and the experimental work through two IRIS Graphics Workstations (3030 and 3130) and two DEC 5000 Workstations. The system, with state-of-the-art, real-time, threedimensional, color-graphics software (PLOT3D), is equipped with an extensive multi-user and multi-task environment with twelve serial lines. Users are able to share the same data base or experimental information. This provides the heart of the interaction of the analytical, computational, and experimental research.

In addition to the super computers at NASA facilities and Princeton/NSF Consortium, the network includes access to the IBM 4341/NM and Harris/VS computers, the IBM 3090 Class VI machine, and the Cray XMP on campus as well as the MASSCOMP. The College of Engineering at ASU is currently also equipped with several VAX/780 and VAX/785 minicomputers exclusively for research purposes (each office and laboratory has a hard-wired RS232 interface). These minicomputers are excellent systems for program development. The IRIS and DEC machines can access all the features available in those minicomputers through the existing local area networking (Ethernet) on the campus. Furthermore, the system can communicate directly with NASA research facilities to share information through telephone couplings. The full array of computer capabilities from super-mini to super-super is in place for the research.

Ray-Sing Lin, a PhD student, and Nay Lin, a PhD student, are the two candidates for the Fellowship. Ray, Nay, and Tom Buter (also a PhD student) each spent one month of the summer of 1991 at Langley Research Center working on these and similar problems, interacting with NASA and ICASE personnel.

The principal investigator for this work is Helen L. Reed, Associate Professor of Mechanical and Aerospace Engineering. Professor Reed has spent the last ten years conducting theoretical and computational research on problems of boundary-layer stability specifically applied to the ACEE/LFC programs. She also spent one month of the summer of 1991 at NASA/Langley Research Center. Her resume is attached as Appendix I. 


\section{HELEN LOUISE REED}

\section{EDUCATION}

Ph.D., Engineering Mechanics, VPI\&SU, Dec. 1981.

M.S., Engineering Mechanics, VPI\&SU, June 1980.

A.B. in Mathematics, Goucher College, May 1977.

\section{AREA OF TEACHING AND RESEARCH}

Supersonics/Hypersonics, Hydrodynamic Stability, Laminar Flow Control, Three-Dimensional Boundary Layers, Receptivity, Separated and Transitional Flows, Unsteady Flows, Aerodynamics, Computational Fluid Mechanics, Perturbation Methods.

\section{POSITIONS HELD}

Sept. 1991-June 1992, Associate Professor (Sabbatical), Inst. Fluid Sci., Tohoku Univ., Scndai, Japan. Aug. 1985 - present, Associate Professor (Tenure awarded Apr. 1988), ASU.

Sept. 1982-Aug. 1985, Assistant Professor, Stanford Univ. Jan. 1982-Aug. 1982, Assistant Professor (Non-tenure track), VPI\&SU. June 1977-Dec. 1981, Aerospace Technologist, NASA/Langley Research Center. Summer 1976, Mathematics Aid, NASA/Langley Research Center.

\section{HONORS / DISTINCTIONS}

\section{Phi Beta Kappa}

Recipient of a NASA fellowship, 1976

Outstanding Summer Employee Award from NASA/Langley Research Center, 1976

Torrey Award for Excellence in Mathematics, Goucher College, 1977

Outstanding Achievement Award from NASA/Langley Research Center, 1978

Cunningham Fellowship Award from Virginia Polytechnic Institute \& State Univ., 1981

Presidential Young Investigator Award, National Science Foundation, 1984

AIAA Excellence in Teaching Award, Arizona State University, Fall 1988

Professor of the Year, Pi Tau Sigma, Arizona State University, 1988-1989

Associate Fellow, American Institute of Aeronautics and Astronautics, December 1990

Faculty Awards for Women in Science and Engineering, National Science Foundation, 1991

\section{PUBLICATIONS}

"Flow over Plates with Suction through Porous Strips," A.H. Nayfeh, H.L. Reed, S.A. Ragab, AIAA J. 20, 5, 587, May 1982.

"Stability of Flow over Axisymmetric Bodies with Porous Suction Strips," A.H. Nayfeh, H.L. Reed, Phys. Fluids, 28, 10, 2990, Oct. 1985.

"Numerical-Perturbation Technique for Stability of Flat-Plate Boundary Layers with Suction," H.L. Reed, A.H. Nayfeh, AlAA J., 24, 2, 208, Feb. 1986.

"Effect of Suction and Weak Mass Injection on Boundary-Layer Transition," W.S. Saric, H.L. Reed, AlAA J., 24, 3, 383, Mar. 1986.

"Flow over Bodies with Suction through Porous Strips," A.H. Nayfeh, H.L. Reed, S.A. Ragab, Phys. Fluids, 29, 7, 2042, July 1986.

"Wave Interactions in Swept-Wing Flows," H.L. Reed, Phys. Fluids, 30, 11, 3419, Nov. 1987.

"Stability of Three-Dimensional Boundary Layers," H.L. Reed, W.S. Saric, Ann. Rev. Fluid Mech., 21, 235, Jan. 1989.

"Numerical Simulations of Transition in Oscillatory Plane Channel Flow," B.A. Singer, J.H. Ferziger, H.L. Reed, JFM, 208, 45, 1989. 
"The Effects of Streamwise Vortices on Transition in the Plane Channel," B.A. Singer, H.L. Reed, J.H. Ferziger, Phys. Fluids A, 1, 12, 1960, Dec. 1989.

"Compressible Boundary-Layer Stability Theory," H.L. Reed, P. Balakumar, Phys. Fluids A, 2, 8, 1341, Aug. 1990.

"An Application of Geometric Deformations Using Triparametric Volumes to Approximate Fluid Flow," S. Kersey, M. Henderson, H.L. Reed, R. Barnhill, acc. Comp. Fluids.

"Stability of Three-Dimensional Supersonic Boundary Layers," P. Balakumar, H.L. Reed, Phys. Fluids A, 3, 4, 617, Apr. 1991.

"A Catalogue of Linear Stability Theory Results," H.L. Reed, acc. Ann. Rev. Fluid Mech., 25, 1993.

"Shepard's Interpolation for Solution-Adaptive Methods," C.-Y. Shen, H.L. Reed, T.A. Foley, submit. $J$. Comp. Phys.

"Application of a Solution-Adaptive Method to Fluid Flow: A Unified Approach," C.-Y. Shen, H.L. Reed, submit. Comp. Fluids.

"Development and Decay of a Pressure-Driven, Unsteady, Three-Dimensional Flow Separation," R.W. Henk, H.L. Reed, submit. JFM.

"On the Linear Stability of Supersonic Cone Boundary Layers," G.K. Stuckert, H.L. Reed, submil. AIAA J.

"Linear Disturbances in Hypersonic, Chemically Reacting Shock Layers," G.K. Stuckerh, H.L. Rccd, submit. AIAA J.

"Analysis of High-Frequency Secondary Instabilities in Three-Dimensional Boundary Layers," H.L. Reed, D.A. Fuciarelli, submit. Phys. Fluids $A$.

"A Numerical Model for Circulation Control Flows," R.G. Holz, A.A. Hassan, H.L. Reed, submit. AlAA J.

"Observations on the Use of Linear Stability Theory in Three-Dimensional Boundary Layers," H.L. Recd, T.S. Haynes, submiL AIAA J.

31 refereed national conference proceedings papers ( 5 invited)

6 books and 7 aricles edited

7 technical reports

\section{PROFESSIONAL SERVICE}

Member of Presidential Young Investigator Workshop on U.S. Engineering, Mathematics, and Science Education for the Year 2010 and Beyond, Washington, D.C., November 4-6, 1990. This is an advisory group to President Bush's Science Advisor, Allen Bromley, concerning the directions U.S. education must take in the preparation and training of the U.S.'s future scientists and lay peoplc.

Member of National Academy of Sciences/National Research Council Aerodynamics Panel which is a part of the Committee on Aeronautical Technologies of the Aeronautics and Space Engineering Board, Commission on Engineering and Technical Systems, November 1990-March 1992. This is the advisory group to NASA and the U.S. Congress concerning the directions NASA must take in order to enable the U.S. to remain competitive in the world arena.

Member of U.S. National Transition Study Group under the direction of Eli Reshotko, 1984-Present.

Associate Editor, Annual Review of Fluid Mechanics, 1986-Present. With the work divided equally among John Lumley, Milton Van Dyke, and myself, we are responsible for complete selection, referecing, and editorial correction of all articles in each yearly volume.

Originator of Annual Picture Gallery of Fluid Motions at annual meetings of the American Physical Sociery, November 1983, Houston. Responsibility for the gallery at American Physical Society meeting at Brown University, November 1984; Eugene, November 1987; Buffalo, November 1988; Palo Alto, November 1989; Cornell, November 1990; Scotusdale 1991.

Member of AlAA Technical Committee on Fluid Dynamics, 1984-1989. APS/AIAA and ASME-AMD/AIAA Liaison. Prepared Aerospace Audit article for Fluid Dynamics, Aerospace America, December 1988 (did not appear because of difficulties between Technical Committee and editors).

Member of Fluid Mechanics Technical Committee of the Applied Mechanics Division of the ASME, 1984. Present.

Member of Steering Committee for National Fluid Dynamics Congress, June 1988-Present.

University Representative of National Science Foundation Fluids Engineering Workshop. Group Leader and Coordinator of final document for Unsteady Flow Panel, Savannah, Georgia, September 17-20, 1986. 
Chairperson of ASME Junior Awards Committee 1989-Present. Vice-Chairperson 1987-1988.

Member of Scientific Committee of 1992-3 IUTAM Symposium on Nonlinear Stability of Nonparallel Flows, January 1990-Present.

Chairperson, 2nd Annual Arizona Fluid Mechanics Conference, Arizona State University, April 4-5, 1986.

Technical Chairperson, AJAA 19th Fluid, Plasma Dynamics, and Lasers Conference, Honolulu, June 1987.

Co-Chairperson, with Dan Jankowski, 44th Annual American Physical Society/Division of Fluid Dynamics Meeting, Scousdale, November 1991.

Co-Organizer with Dr. Daniel Reda (Sandia National Laboratories) of Symposium on Experimental and Theoretical/Numerical Studies of Boundary-Layer Stability and Transition, at the First Joint ASMEIJSME Fluids Engineering Conference, Porland, June 23-26, 1991.

Chair of 21 various symposia and sessions at international conferences.

CONSULTING

Westinghouse Electric and Naval Underwater Sea Center (1981)

Pratt and Whitney (1986-1991)

ICASE Consultant, NASA/Langley Research Center (Current)

Colorado Research Development Corporation (Current) 